\title{
Otra regulación interina de la incapacidad temporal. La eterna anarquía regulatoria de una contingencia transitoria
}

\author{
Víctor Fernando Manrique López \\ Catedrático de Derecho del Trabajo \\ Universidad de Deusto
}

Recibido: 26.07.2010

Aceptado: 02.09 .2010

La Incapacidad Temporal se conoce con su actual denominación desde la Ley 42/94 de 30 de diciembre, eliminando del glosario de conceptos de la Seguridad Social la denominada Incapacidad Laboral Transitoria y queda definida como "aquella situación en la que se encuentran los trabajadores impedidos temporalmente para trabajar debido a enfermedad común o profesional y accidente, sea o no de trabajo, mientras reciban Asistencia Sanitaria de la Seguridad Social, así como los periodos de observación por Enfermedad Profesional en los que se prescriba la baja en el trabajo durante los mismos".

El objetivo de esta prestación no es otro que el de subvenir a las necesidades económicas a las que se ve avocado quien deja de percibir sus retribuciones salariales. De ahí, como se ha apuntado, la tradicional búsqueda de la Entidad Gestora por descubrir la piedra filosofal del control de la gestión de la IT para detener el incremento de gasto que esta prestación ha experimentado con el tiempo.

Es también, una de las causas de suspensión del contrato de trabajo, según establece el Art. 45 del Estatuto de los Trabajadores, y, por lo tanto, exonera de las obligaciones reciprocas de trabajar y de remunerar el trabajo.

La alteración de la salud unida a la pérdida de ingresos derivados del trabajo es lo que constituye, como se ha indicado, la situación de necesidad, conllevando la reserva del puesto de trabajo mientras dure la causa legal de la suspensión.

El control del gasto, derivado de la Incapacidad Temporal, es un clásico del legislador o como señalaba el profesor Mercader, y constituye una tradición a la vez que un rasgo unificador de las reformas que en los últimos 30 años se han producido en materia de Seguridad Social.

Un repaso no excesivamente pormenorizado de una cualquiera de las colecciones legislativas, evidenciaría, a simple vista, que la regulación de la otrora Incapacidad Laboral Transitoria, es la que más cambios legales y reglamentarios ha sufrido. "Estos cambios han afectado a todos los aspectos que la integran: a su denominación, a su concepto, a su duración, a su cuantía y a su gestión; su falta de estabilidad normativa es reflejo de su trascendencia, complejidad y conflictividad" (Rocío Molina González Pumariega). 
Las razones a las que responden los numerosos cambios legislativos, son de distinto índole pero, en última instancia, convergen en una única causa, el ingente y constante incremento del coste, en primer término económico de esta prestación (tasas de crecimiento de un 14\% hasta el 2007 y a un descenso del $11 \%$ para los primeros ocho meses del 2009; si bien, en el primer trimestre del 2010 se ha producido un notable incremento) y en segundo término, también el coste social de la contingencia protegida, y en la imperiosa necesidad de mejorar la eficacia de su gestión.

Las reformas que se han venido sucediendo se han producido para contener su crecimiento e intentar reducir su coste, entre otros motivos, aumentando, al mismo tiempo, las medidas de control sobre el nacimiento y la dinámica de la misma, con objeto de evitar las situaciones de abuso y fraude.

Así, las reformas de los últimos años en la materia, debido a ese incremento constante y alarmante del gasto en Incapacidad Temporal, se han centrado de manera casi exclusiva en la ordenación de sus mecanismos de control, en base a la idea de que un mayor control llevará a una reducción del gasto (Tortuero Plaza).

No sólo, por tanto, las Entidades Gestoras están interesadas en una mejor gestión de esta contingencia sino las propias empresas, pues, como se ha indicado, no es sólo un problema económico, sino también uno de los principales problemas de la gestión empresarial, puesto que supone una pérdida de dinero y una pérdida de productividad; no debiéndose olvidar, que la Incapacidad Temporal, o baja laboral a la que se acogen los trabajadores, supone ya un $80 \%$ del total del absentismo laboral que registra una empresa. Un dato más, la IT representó en el año 2008 el 69,3\% de las horas no trabajadas. Sólo en el año 2007 se perdieron prácticamente seis días (44,5 horas) de trabajo por trabajador

Libros de todas las gamas cromáticas han incidido en esta materia, sobre la premisa de la presunción de fraude en la obtención y mantenimiento de esta prestación, el libro blanco en 1977, el libro rojo en 1981, el libro verde del mismo año, el libro naranja en 1985, secundados por diferentes reformas legales entre las que destacan en la línea del permanente recorte, el Real Decreto 53/1980, de 11 de enero, que reduce en las contingencias comunes el porcentaje aplicable a la base reguladora para determinar el subsidio, desde el $75 \%$ al $60 \%$, durante los días $4 .^{\circ}$ a $20 .^{\circ}$ ( con el objetivo de penalizar las bajas de corta duración), y aquella que trasladó al empresario el coste de esta prestación entre los días $4 .^{\circ}$ a $15 .^{\circ}$ (con ánimo de ahorro de su coste: para las Gestoras) en consonancia con experiencias comparadas en países europeos; si bien con menor incidencia sobre los empleadores patrios. Me refiero al R.D Leg. 51/92, cuya constitucionalidad cuestionada sobre la base de una quiebra de las garantías públicas de nuestro sistema, fue rechazada por un entonces más diligente Tribunal Constitucional, en su sentencia de 10 de febrero de 1994 (n. 37/1994) al decir: "Como ha afirmado el Tribunal Cons- 
titucional (STC 37/1994, de 10 febrero) el derecho a la Seguridad Social es un derecho de estricta configuración legal, que admite dentro de un sistema de protección social pública (artículo $41 \mathrm{CE}$ ) supuestos de responsabilidad privada, siempre que no se altere sustancialmente el régimen de cobertura pública. El hecho de que el artículo 131 citado -y preceptos de que traen origen- admita e imponga la obligación al pago, durante un período determinado, de la prestación o subsidio de Incapacidad Temporal al empleador, únicamente conlleva la modificación de la obligación por sustitución de la persona del deudor (conforme el artículo 1203.2.. ${ }^{\circ}$ del Código Civil), pero no su novación o extinción (según reiterada doctrina de la Sala Primera de este Tribunal -entre otras Sentencias, la de 24 junio 1988 ( la novación por cambio del deudor no se presume, sino que ha de resultar de modo inequívoco). Tribunal, que hoy, válgame la digresión, rechaza más del 99\% de los recursos de amparo que se presentan y anda escaso de tiempo e ingenio para resolver aquellos que acucian.

En relación con lo anterior, se debe recordar que la Entidad Gestora también pretendió quedar fuera del abono de este periodo de IT, a lo que el Tribunal Supremo puso coto con su doctrina. En sentencia de 15 de junio de 2008, pronunciándose a favor de la responsabilidad subsidiaria de la entidad gestora, que está obligada a adelantar el importe de la prestación, sin perjuicio de su derecho a repetir contra la empresa incumplidora. Se afirmaba en la sentencia que "no habiendo variado esencialmente la naturaleza y objeto de la prestación, que incluso sigue conservando este nombre y carácter, y, a falta de disposición legal en sentido contrario, debe permanecer y subsistir el sistema de obligaciones y garantías accesorias establecidas para la prestación litigiosa en el régimen público de Seguridad Social para los supuestos de incumplimiento de la obligación prestacional por parte del empresario directamente obligado a su pago, y ello, sin perjuicio del derecho de la entidad gestora a reintegrarse posteriormente del empresario incumplidor, en ejercicio de las facultades que le confiere tal cualidad de entidad gestora de la Seguridad Social. En definitiva, el trabajador ha causado derecho a la prestación de Incapacidad Temporal y la responsabilidad de su pago debe imponerse "ex lege" al sujeto obligado, que es el empleador actual (artículo 126.1 LGSS), pero ello no impide -a falta de norma expresa en sentido contrariola responsabilidad subsidiaria de la entidad gestora, sin perjuicio de que ésta se subrogue en los derechos del beneficiario (artículo 126.3 LGSS)".

No podemos ignorar, que estos intentos de ahorro o de desincentivación de un absentismo retribuido y sobre el que pesa, en muchas ocasiones, la presunción de la picaresca, han quedado incentivados por la negociación colectiva al pactarse en los Convenios complementos del subsidio. Ahora bien, para ello hay que obtener previamente la baja.

A la preocupación de los responsables, gestores y políticos, tampoco en su momento, fue ajeno el Pacto de Toledo, que, en su recomendación 13. ${ }^{\mathrm{a}}$ afirmaba "la necesidad de adoptar medidas destinadas a mejorar la gestión 
de las prestaciones por Incapacidad Temporal y por invalidez, al objeto de frenar las causas de fraude dentro del sistema público en el acceso y permanencia de las prestaciones. Entre dichas medidas tendrán prioridad el establecimiento de un calendario y de los medios humanos necesarios para el control de dicha incapacidad desde el mismo sistema y profundizar en la participación y corresponsabilidad social en la gestión, control y vigilancia de estas prestaciones".

Al mencionado Pacto siguió un proceso de concertación social que se consolidó el 9 de octubre de 1996, fecha en la que se suscribe el Acuerdo entre el Gobierno y las organizaciones sindicales más representativas, sobre Consolidación y Racionalización del Sistema de la Seguridad Social, y en él se reitera la necesidad de combatir el recurso indebido a la Incapacidad Temporal y la necesidad de mejorar los mecanismos de control de la prestación

El Pacto de Toledo, apuesta definitivamente por la necesidad de mejorar, no la gestión de la Seguridad Social en general, sino la de la prestación de Incapacidad Temporal, entre otros, con el fin de corregir el fraude en su disfrute.

Para conseguirlo se propuso la dotación de los medios humanos precisos para llevar a cabo un adecuado control, así como la intensificación de la participación en dicho control. En este sentido, al Instituto Nacional de la Seguridad Social se le dotaba de la facultad de comprobar las situaciones de Incapacidad Temporal y de proponer en su caso altas al Servicio Público de Salud correspondiente y de la posibilidad de emitir altas médicas a los exclusivos efectos de la prestación económica de IT, sin perjuicio de que el trabajador siguiera precisando y recibiendo asistencia médica por parte de los Servicios Públicos de Salud (art. único del RD 1117/1998, que desarrolla la Ley 66/97, de 30 de Diciembre y en concreto su art.38, lo que se tradujo en un sin fin de procedimientos judiciales, con no muy buenos resultados judiciales para el INSS. Esta misma competencia se extendió a los médicos de las Mutuas de Accidente de Trabajo y Enfermedades Profesionales RD-Ley $6 / 2000$, de 23 de Junio (aunque pendiente del posterior desarrollo reglamentario. No obstante, el citado reglamento no se ha materializado debido a la frontal oposición de las organizaciones sindicales, una vez más) y a los médicos adscritos al Instituto Social de la Marina (Ley 55/1999, de 29 de Diciembre).

Con el mismo propósito de restringir el abuso en la Incapacidad Temporal y la obsesión en la lucha contra el fraude se suscribe el Acuerdo para la mejora y el desarrollo del Sistema de Protección Social, en 9 de abril de 2001

El Acuerdo (en su apartado décimo, denominado lucha contra el fraude) profundiza en el contenido de la Recomendación 13. ${ }^{\mathrm{a}}$ del Pacto de Toledo y contaba como propuesta de la "gestión de la Incapacidad Temporal, de modo que dando cobertura a las situaciones reales de imposibilidad de acceder al trabajo en caso de enfermedad o accidente, se evite la utilización indebida de esta prestación. 
Con este objetivo se proponía:

- Que se establecieran las medidas necesarias que impidan la concatenación abusiva de la IT con la prestación de Desempleo.

- Que se articularan las medidas que evitaran la prolongación indebida de la prestación, en los casos en que el trabajador que es llamado a reconocimiento médico por los servicios médicos de la Entidad responsable del pago de la prestación, no acuda a los mismos sin causa justificada.

- Que se incrementaran las medidas de coordinación necesarias entre las Entidades responsables del pago de la prestación de IT y el INSALUD y los Servicios de Salud, que permitieran un mejor control de las situaciones de IT.

Cabe concluir, como señala la doctrina, que se produjeron importantes y progresivos recortes para evitar la enfermedad de corta duración y para el control de la situación, pero no se logró atajar otros problemas, como la imposibilidad de recaídas cuando ya se hubiese agotado la duración máxima o se hubiera reconocido al trabajador a efectos de la declaración de una Incapacidad Permanente, denegada en vía administrativa, en virtud de la ejecutividad del acto administrativo, que inexorablemente forzaban el recurso al fraude como único medio de solucionar una situación en la que el trabajador se hallara realmente imposibilitado para trabajar y el empresario no pudiera destinarle a ningún trabajo sin menoscabo de su salud.

Haciendo uso de esa incontinencia reguladora que aparece vía ley de presupuestos, a través de la correspondiente a los presupuestos del año 2002 (Ley 24/2001, de 27 de Diciembre) se incorpora al art. 131 bis, como causa de extinción la incomparecencia injustificada a cualquiera de las convocatorias para los exámenes y reconocimientos médicos ordenados por los médicos adscritos al INSS o a la Mutua, medida refrendada, casi de forma general por los Tribunales (Sentencia del Tribunal Supremo de 15 de marzo de2007 y del Tribunal Superior de Justicia de Andalucía, Sala de lo Social de Sevilla, de 18 junio de 2003 y Sentencia del Tribunal Superior de Justicia del País Vasco de 24 enero de 1994).

Pese a que dicha conducta está tipificada como infracción grave en el artículo 25-2 y 47 -1, a y b, de la Ley de Infracciones y Sanciones del Orden Social (modificada a su vez por la Ley 45/2002), la contradicción se ha salvado por el Tribunal Supremo a favor del control de la Incapacidad Temporal, considerando que la decisión extintiva se incluye en el ámbito propio de la gestión de la contingencia de la Incapacidad Temporal, fundamentando tan peculiar consideración en que "la inclusión en la Ley de Infracciones y Sanciones del Orden Social, por un texto normativo que viene referido al establecimiento de medidas urgentes para la reforma del sistema de protección por Desempleo y mejora de la ocupabilidad "sin que entre en sus designios 
normativos la modificación de la Incapacidad Temporal" (sentencias del Tribunal Supremo de 7-3-07,15-3-07 y 7-2-08).

Se introdujo un nuevo apartado primero, al número 3 del artículo 131 bis de la LGSS, en el que se prevé la obligación de cotizar durante la situación de Incapacidad Temporal, pretendiendo con esta medida dar solución a las lagunas en la cotización del trabajador que surgen a lo largo de la vida laboral del mismo, mientras está pendiente de la declaración de Incapacidad Permanente.

Esta ley presupuestaria para el ejercicio 2002, también con nocturnidad, modifica el artículo 222 de la LGSS en supuestos de concatenación de periodos de Incapacidad Temporal y Desempleo, con el fin, una vez más de ahorrar en el pago de las prestaciones. Esta norma, para el supuesto en el que la Incapacidad Temporal por contingencias comunes se produce antes de haberse extinguido el contrato, limita la cuantía de la prestación económica al importe de la prestación contributiva por Desempleo y, se descuenta el tiempo de I.T. de la prestación por Desempleo a que tuviere derecho, que se entiende consumida en el mismo periodo de I.T.

Además, se reducía la cuantía de la prestación de Incapacidad Temporal, cuando ésta se causa una vez extinguido el contrato y se extiende por el tiempo de la duración de la prestación de Desempleo, pues, una vez trascurrido este plazo, se reduce al $80 \%$ del IPREM.

Con estas medidas, se evitaba la práctica de iniciar una Incapacidad Temporal, justo antes de ser despedido, como refugio o medida que posponía el inicio de la prestación por Desempleo.

Con la renovación del pacto de Toledo, en el año 2003 se incide nuevamente, a través de su recomendación octava, en la "Necesidad de seguir avanzando en la adopción de medidas destinadas a mejorar el control de las prestaciones de Incapacidad Temporal e Invalidez al objeto de evitar prácticas abusivas en relación con las mismas". Todo ello dará lugar a nuevas previsiones normativas en la materia.

Consecuencia y fruto de todo esto, son las reformas legislativas dirigidas a mejorar la gestión y control de esta prestación que se han ido sucediendo desde la, todavía hoy vigente, Orden de 13 de octubre de 1967; la Orden de 6 de abril de 1983, la Ley 42/1994, que supuso que la tradicional ILT y la Invalidez Provisional (que permitían acumular hasta seis años de baja) constituyeran una única contingencia que adoptaría la denominación que ha llegado hasta el día de la fecha, si bien, por mor del ahorro, con un recorte, en esta ocasión, por la vía de la duración y no en el de la cuantía como ocurrió en 1980; el Real Decreto 575/1997 y la Orden de 19 de junio de 1997 (modificadas respectivamente por el RD 1117/1998 y la O. de 18 de septiembre de 1998), que constituyen la normativa básica en materia de control de la Incapacidad Temporal, que vendrán a regular determinados aspectos de la gestión y control de la prestación económica de la Seguridad social por Incapacidad Temporal, estableciéndose determinados controles en la comprobación 
del mantenimiento del derecho a la prestación económica por Incapacidad Temporal en orden a asegurar la efectividad en el percibo de las prestaciones económicas de la Seguridad Social por Incapacidad Temporal y evitar la utilización indebida de la protección, cuando no el fraude por lo que se refiere a la gestión, control y procedimiento de la IT hasta el cumplimiento del duodécimo mes.

Tampoco contribuyeron a acortar la duración de los procesos las prácticas de los médicos, que llegados los doce meses, por regla generalísima, no emitían el informe, por las razones que fuere, en el que se debían describir las dolencias padecidas por el interesado y las limitaciones de su capacidad funcional, así como la presunción de que, dentro del período subsiguiente de seis meses, aquél pueda ser dado de alta por curación, razón por la cual el proceso medio era de 18 meses.

No debemos olvidarnos de los convenios de colaboración entre las administraciones públicas (Ministerio y Comunidades Autónomas) implicadas, que, en esta materia, se vienen suscribiendo desde el año 2006, con el fin de involucrar a los facultativos en el control de la IT.

Alcanzamos en este periplo temporal, la ulterior y tan criticada por la doctrina reforma del art. 128 de la LGSS y 131 bis por la Ley de Presupuestos para 2006 ( Ley 30/2005), que, en su Disposición Adicional 48. a declara al INSS, agotado el plazo de duración de doce meses a través de los órganos competentes para evaluar, calificar y revisar la Incapacidad Permanente del trabajador, como el único competente para reconocer la situación de prórroga expresa con un límite de seis meses más, o bien, para determinar la iniciación de un expediente de Incapacidad Permanente, o bien, para emitir el alta médica, a los exclusivos efectos de la prestación económica por Incapacidad Temporal. El Instituto Nacional de la Seguridad Social será así el único competente, tanto para determinar si una nueva baja médica tiene o no efectos económicos, cuanto para emitir cualquier baja médica que se produzca en un plazo de seis meses, posterior a la antes citada alta médica por la misma o similar patología».

Reforma, por cierto, que trata de superar la doctrina jurisprudencial del Tribunal Supremo, que, en sentencia de 20 de febrero de 2002, ratificada posteriormente en sentencias de la propia Sala, como las de 22 de octubre de 2002, de 28 de octubre de 2003 o de 8 de noviembre de 2004, entendía en unificación de doctrina que cuando se agotaba la duración máxima de la IT, y se volvía a trabajar y rebrotaba la misma patología, generando una nueva baja, surgía el derecho al subsidio si existía una cotización de 180 días en los últimos cinco años, aunque no se hubiera trabajado durante seis meses entre uno y otro proceso. En la última de las sentencias citadas se afirma "que dichos posibles abusos o fraudes se deben atacar con los medios de la Inspección a disposición de la Entidades Gestoras, y no mediante la negación de las prestaciones a quienes han conseguido de nuevo completar los requisitos para su obtención". 
Sin embargo la experiencia ha demostrado que no se ha logrado este objetivo, al evitarse, mediante el sencillo remedio de cambiar la clave médica relativa al diagnóstico de los sucesivos procesos de Incapacidad temporal. A esta picaresca ayuda el que no coincidan los códigos de diagnósticos empleados por los médicos del Servicio público de salud y los utilizados por los facultativos del INSS, y que el Sistema informático utilizado sólo permita la introducción de un solo código numérico por cada proceso de Incacapacidad Temporal, aunque concurran varias patologías. En consecuencia, un simple cambio del diagnóstico permite concatenar procesos pese a los esfuerzos del legislador.

Reforma que además, en palabras de Sempere Navarro, pretendía combatir los procesos de IT (acortándolos), la prevalencia de los criterios médicos (restringiendo sus efectos) o las recaídas (controlándolas), concediendo un mayor protagonismo al INSS, y evitando la disociación entre las decisiones adoptadas por los Servicios de Salud y por la Entidad Gestora.

Recorta esta reforma el plazo máximo de 30 meses que se podía mantener en situación de Incapacidad Temporal, ya que si bien continua manteniendo la necesidad de que, cuando la situación de Incapacidad Temporal se extinga por el transcurso del plazo máximo fijado en el párrafo primero del art. 128.1.a), sea en el plazo «de doce meses o, en su caso, hasta de dieciocho meses», se examine, en el plazo de tres meses, el estado del incapacitado a efectos de su calificación en el grado que corresponda, como Inválido Permanente. Como nuevo recorte señala que «no obstante lo previsto en el párrafo anterior, en aquellos casos en que continúe la necesidad de tratamiento médico, por no ser definitivas las reducciones anatómicas o funcionales que presente el trabajador, se valorará y calificará la situación de Incapacidad Permanente en el grado que corresponda, declarando la situación revisable en el plazo de seis meses».

Es decir, se amplió la prórroga de los efectos de la Incapacidad Temporal, mediante un período de Incapacidad Permanente Provisional, que no existe en la actualidad, tras la reforma que supuso la Ley 40/07, que establece en materia de prorroga que «en aquellos casos en los que, continuando la necesidad de tratamiento médico por la expectativa de recuperación o la mejora del estado del trabajador, con vistas a su reincorporación laboral, la situación clínica del interesado hiciera aconsejable demorar la citada calificación, ésta podrá retrasarse por el período preciso, que en ningún caso podrá rebasar los veinticuatro meses siguientes a la fecha en que se haya iniciado la Incapacidad Temporal».

Es destacable, que, tras la reforma, la necesidad de continuar el tratamiento se condiciona a las expectativas de recuperación o mejora de su estado con vistas a su reincorporación laboral.

En definitiva, se retoma la situación preexistente, en cuanto que quien se vea impedido para trabajar va a continuar en situación de IT y no de Inca- 
pacidad Permanente, aunque sin recuperar aquella duración máxima de treinta meses. El proceso de recorte es imparable e irrevocable.

Por otra parte, el iniciado proceso de asunción de competencias por el INSS, previstas en el art. 128 1.a) de la LGSS con la Ley 30/05, se culminó y completó con la Resolución de la Secretaría de Estado de 14 de enero de 2008, en materia de gestión de esta prestación (dos años despuers del inicio realizado por la Resolución de fecha 16 de Enero de 2006).

Un nuevo acuerdo social, en este caso, el alcanzado sobre medidas en materia de Seguridad Social, de 13 de Junio de 2006 es el predecesor y causa de la Ley 40/07, de 4 de diciembre.

Las sucesivas reformas, habían garantizado el caos y la inseguridad jurídica y una nada deseable descoordinación entre las Gestoras y los Servicios de Salud, amén de reiteradas críticas de la doctrina, que imputaba al INSS la injerencia en competencias exclusivas de la Administración sanitaria, y criticaba sus omnímodas facultades ajenas a un previo control por la Inspección médica y la inseguridad constatada en la realidad que ello podía suponer en atención a la descoordinación entre servicios de Salud y Gestora.

La cada vez mayor asunción de competencias por el INSS, en esta materia iniciada, en el año 98 y culminada en el 2005, como destacaba Sempere, provocaba, desde una perspectiva estrictamente práctica, situaciones kafquianas, que desembocaban en auténticas situaciones de desprotección para el trabajador.

Así, era posible que el INSS, en el ejercicio de sus competencias, emitiera el alta a los exclusivos efectos económicos, (por eso de respetar las competencias, sanitarias y no herir susceptibilidades autonómicas), y que el facultativo del Servicio de Salud continuara expidiendo partes de baja o de confirmación, llevando al trabajador a situaciones muy delicadas como se puede comprender. A saber: el trabajador se encontraba con un alta del INSS con plena eficacia y con una baja médica, obviamente expedida en contradicción con el alta del INSS, y que justificaba a su vez que el trabajador estaba inhabilitado para trabajar y precisaba asistencia sanitaria, de tal forma que no percibía retribución de ningún tipo, pudiendo verse avocado a la pérdida de su trabajo por no presentarse a su puesto en la empresa.

Los Tribunales, obviamente, consideraron que la baja médica constituía título suficiente para que surgiera, en su caso, la suspensión del vínculo laboral y la situación de IT, pero no para generar el derecho a la percepción del subsidio.

Estas situaciones de inadmisible descoordinación, en relación con la Incapacidad Temporal, se han pretendido superar con la Ley 40/07.

La norma, preservando las facultades que en materia de control de IT había ido asumiendo el INSS, regula un procedimiento para aquellas altas que los facultativos adscritos al INSS, en su actividad de control, emitan, agotado el plazo de 12 meses. 
Este procedimiento, sin entrar en detalles en cuanto a su tramitación, se caracteriza porque permite al trabajador discrepar del alta médica ante la Inspección médica, que se deberá pronunciar sobre el alta mostrando su conformidad o disconformidad (también cabe el silencio, previsto y de naturaleza negativa). Se logra de esta manera garantizar el mantenimiento del subsidio hasta la decisión final, en un proceso que puede extenderse hasta un máximo de 18 días y por otra parte una mejor coordinación entre administraciones.

Pero no sólo a ello se entrega la Ley 40/07, sino que en la línea de mantener un régimen jurídico diferenciado, que cuanto antes deberá superarse, resulta que, para las contingencias profesionales, da una nueva redacción al art. 222.1 de la LGSS, que regula la concatenación de las prestaciones de Incapacidad Temporal y de Desempleo, estableciendo la posibilidad de que, cuando la Incapacidad Temporal derive de un riesgo profesional, y durante la misma se extinga el contrato de trabajo, el interesado pueda seguir percibiéndola hasta el alta médica, sin consumir periodo de prestación de Desempleo, si después accediera a esta prestación.

Una vez más contemplamos atónitos, como aquel trabajador, que ha sufrido un Accidente laboral o padecido una Enfermedad profesional está mejor protegido, que aquel cuya situación tiene una etiología común, pese a encontrarse ante la misma situación de necesidad por la pérdida de su empleo, ya que el primero no consume Desempleo, y su prestación económica es superior, en tanto en cuanto seguirá percibiendo el subsidio de Incapacidad Temporal en la misma cuantía que tuviera reconocida, mientras que el segundo verá descontado del periodo de Desempleo, como consumido, el que hubiera permanecido en Incapacidad Temporal, y el importe de esta será el que corresponda al Desempleo.

En favor de la reforma, se debe recordar que esta norma introduce una modificación, en contra de los pronunciamientos judiciales favorables a la Entidad Gestora ( Sentencias del Tribunal Supremo de 17-9-2007, 20-112007, 23-1-2008, 19-5-2008 y 29-5-2008), en aquellos casos de trabajadores que viendo extinguido su contrato de trabajo en situación de Incapacidad Temporal, pasaban, sin solución de continuidad, a situaciones de Incapacidad Permanente, o Jubilación, o se producía su fallecimiento causando prestaciones de Muerte y Supervivencia, sin haber solicitado la prestación de Desempleo, razón por la que durante ese periodo de Incapacidad Temporal nadie cotizaba y veían minorada su base reguladora para aquellas prestaciones. La nueva redacción, supera aquella interpretación del INSS que había sido avalada por los Tribunales, obligando a la Entidad Gestora de las prestaciones por Desempleo a efectuar las cotizaciones a la Seguridad Social, incluso cuando, habiéndose solicitado la prestación por Desempleo, se pasase, sin solución de continuidad, a una situación de Incapacidad Permanente o Jubilación, o se produjera el fallecimiento del trabajador con derecho a prestaciones de Muerte y Supervivencia.

Tras esta última gran reforma, con el RD 1430/2009 se cumple con la 
obligación de proceder a su desarrollo reglamentario y a aclarar algunas dudas que el procedimiento legalmente suscrito producía en la práctica, quedando completado de esta forma el nuevo modelo de control de la Incapacidad Temporal.

En lo que a este estudio respecta, interesa destacar:

- Lo relativo a la comunicación informática por parte de los Servicios públicos de salud, al cumplirse el duodécimo mes en los procesos de Incapacidad Temporal.

- Los supuestos en que debe aplicarse, por parte de las empresas, organismos públicos y entidades gestoras, la figura del pago delegado de la prestación económica por Incapacidad Temporal.

- Las condiciones exigidas en el procedimiento de disconformidad con el alta médica, emitida por las entidades gestoras introducido por la Ley 40/07.

- Asimismo, se regula detalladamente el procedimiento administrativo de revisión de las altas médicas expedidas por las entidades colaboradoras en los procesos de Incapacidad Temporal.

En este orden de cosas, el Real Decreto regula la comunicación informática por parte de los Servicios Públicos de Salud, al cumplirse el duodécimo mes en los procesos de Incapacidad Temporal. De esta manera se trata de solventar un endémico problema de descoordinación entre administraciones, y, así, literalmente se indica que a efectos de una adecuada coordinación el Servicio Público de Salud, una vez expedido el último parte de confirmación anterior al transcurso de los 12 meses, en el acto del reconocimiento médico deberá comunicar al interesado ( o a quien le represente), que a partir de ese momento corresponderá al INSS o al ISM, el control de su situación, debiendo, a su vez, comunicar esta circunstancia mediante procedimiento informático a la Entidad Gestora competente. Esto implica que, a partir de ese momento, el Servicio Público de Salud no pueda expedir nuevos partes de confirmación de la baja médica. Ello exigirá de las Entidades Gestoras las correspondientes comunicaciones al interesado, a la empresa y, en su caso, a las entidades colaboradoras y al Servicio público de Empleo.

Se trata, en definitiva, de disipar las dudas, más de una vez constatadas, sobre la ausencia de coordinación y las competencias de las administraciones intervinientes.

De forma nítida queda constatado que el control de esta situación, a partir de los doce meses, será exclusivo de las Entidades Gestoras, y no será posible yá, extender mas partes de los de confirmación, que surgían como setas tras la lluvia, y que el facultativo del Servicio Público de Salud no se resistía a emitir, lo que no es óbice para que se le siga asistiendo desde un punto de vista estrictamente sanitario, resultando que la Entidad Gestora será la que se responsabilizará de las correspondientes comunicaciones, tanto a la 
empresa como al trabajador, o a los distintos organismos que deban intervenir.

Las referidas comunicaciones, obviamente, versarán sobre alguno de los pronunciamientos que viene obligada la entidad a realizar, a saber relativos a prórroga, inicio del expediente de Incapacidad o alta por curación, y que necesariamente deben ser conocidos en todos los casos por el interesado, y en otros por las empresas y, en su caso, por los demás organismos que intervengan, incluido el Servicio Público de Empleo. Piénsese, por ejemplo, en una prórroga de un trabajador que se encuentra en situación de Desempleo con derecho a prestaciones.

Parece obvio que el concepto indeterminado que supone la expresión «adecuada coordinación», y al que responde la previsión reglamentaria constituirá, en su puesta en práctica, la clave de bóveda que garantice el soporte del modelo de control diseñado.

El art. 2 del Real Decreto regula el pago de la prestación económica, superando, con ello, el vacío legal que contenía la Ley 30/2005, con el fin de evitar duplicidades o falta de coordinación en el pago, que hasta ese momento, de forma delegada, se efectuaba por la empresa, como señala José Mario Paredes Rodríguez, Letrado de la Seguridad Social, en un recientísimo artículo ("Real Decreto 1430/1990, de 11 de septiembre. La culminación de un nuevo modelo de control de la Incapacidad Temporal").

Especifica el señalado precepto, que la colaboración obligatoria (previsto en el art. 77.1.c) de la LGSS y artículos 3 y 16 de la O. De 25 de noviembre de 1966) en el abono de la prestación cesará el último día del mes en que la Entidad Gestora haya dictado la resolución de prórroga de forma expresa o la iniciación de un expediente de Incapacidad Permanente, si bien y como excepción continuarán abonando el subsidio hasta la extinción de la situación de IT o hasta la calificación de la Incapacidad Permanente, las empresas autorizadas para colaborar en la gestión de la IT, al igual que las Corporaciones locales respecto de aquel personal que le vinieran reconociendo y abonando la IT, de conformidad con la Disposición Transitoria quinta del RD 480/1993, de 2 de abril, por el que se integra en el Régimen General el Especial de los funcionarios de la Administración Local.

Se introduce, de esta forma, un nuevo supuesto de extinción de la obligación de pago delegado por la empresa, trasladándose a la Entidad Gestora competente.

Junto a las excepciones referidas de no finalización de la colaboración obligatoria, relativas a las autoaseguradoras y Corporaciones locales, el n. 3 del art. 2 mantiene esta obligación de pago al Servicio Público de Empleo Estatal, en los casos en los que se declare por la Entidad Gestora competente la prórroga expresa de la Incapacidad Temporal, cuando el trabajador, que se encuentre percibiendo la prestación de Desempleo total pase a la situación de Incapacidad Temporal, en cuyo caso su cuantía será igual a la prestación de Desempleo, si bien dependiendo de que aquella situación de IT, que se 
inicia, constituya o no, recaída de un proceso anterior, y se mantenga, finalizado el plazo de la prestación de Desempleo, en cuyo caso seguirá percibiendo el subsidio en el primer supuesto (que constituya recaída), en la misma cuantía en la que la venía percibiendo, y en el segundo en cuantía igual al $80 \%$ del IPREM mensual vigente, de tal forma, que el periodo máximo al que se extenderá la obligación de pago delegado al Servicio Público de Salud, será el de la duración de la prestación por Desempleo.

Los artículos 3 y 4 regulan el procedimiento de disconformidad con el alta médica emitida por las entidades gestoras y el procedimiento de revisión de las altas médicas, expedidas en los procesos de Incapacidad Temporal. El primero de ellos responde al futuro desarrollo reglamentario, que anuncia el art. $^{\circ} 1$ de la Ley 40/07, y el segundo a lo previsto en la Disposición Adicional Decimonovena de la citada norma ("Reglamentariamente se regulará el procedimiento administrativo de revisión, por el INSS y a instancias del interesado, de las altas que expidan las entidades colaboradoras en los procesos de Incapacidad Temporal").

Los Letrados de la Seguridad Social son quienes pueden dar fe del incremento exponencial de altas médicas que se están dando por los médicos del INSS, y del incremento de la litigiosidad vinculada a este hecho; pero dicho esto, no es menos cierto que la instauración del procedimiento de disconformidad con la implicación de la Inspección médica y la ulterior intervención de los facultativos adscritos al INSS, como peritos (al menos en algunas provincias), han contribuido a que estos actos médicos se vean refrendados en un porcentaje elevadísimo por Juzgados y Tribunales.

Como anteriormente se indicó, la Ley 40/07 implantó un procedimiento que permitía al interesado discrepar ante la Inspección médica, mostrando su disconformidad y no sólo ello sino garantizando, también, que esta decisión no fuera gravosa para el trabajador, que no se vería privado del subsidio, sino cuando la resolución del INSS o el ISM deviniera definitiva.

Llama la atención, que el legislador optara, cuando reguló el procedimiento de disconformidad en el art. 128.1 de la LGSS, por descender a un detalle propio de un reglamento, dejando con ello escaso margen al ulterior desarrollo reglamentario; si bien, no es menos cierto, que la remisión reglamentaria se remitía a la forma de efectuar las comunicaciones previstas en el mismo, así como a la obligación de poner en conocimiento de las empresas, las decisiones que se adopten y que les afecten, provocando que las previsiones del Real Decreto que comentamos recuerden más, en palabras de Francisco Javier Fernández Orrico a un "folleto informativo relativo a las formas de cumplimentar los modelos, que se ponen a su disposición para reclamar".

Podría pensarse, que aquella previsión y el detalle de la regulación de la discrepancia frente al alta, respondiera a la necesidad de poner en marcha el sistema diseñado con la máxima urgencia, y que pudiera haber quedado retrasado en el tiempo por la proverbial tendencia de nuestros gobernantes a 
dilatar en el tiempo los desarrollos reglamentarios, máxime si se espera eternamente a conocer la opinión de los agentes sociales

Poco añade el art. 3, al regular el procedimiento de discrepancia a las previsiones del art. 128 de la LGSS. En el precepto se reitera que el interesado, en el plazo máximo de cuatro días naturales, los siguientes a la notificación de la resolución ( previsión reglamentaria), podrá exponer su disconformidad ante la inspección Médica del Servicio Público de Salud debiendo presentarla ( se cumplimentará en el modelo aprobado, exige la regla primera) en modelo normalizado que estará a disposición en las páginas Web de las Entidades ( es de esperar que también en algún otro lugar, para quien no disponga de esa tecnología) pudiendo presentarla, igualmente ante cualquiera de los órganos señalados en el art. 38.4 de la LRJPCA, momento a partir del cual entrarán en juego distintas posibilidades, dependiendo de la postura que adopte la Inspección, asumiendo o no el criterio del INSS o del ISM, o de que ante esta segunda posibilidad, las Entidades asuman o no la propuesta de reconsideración que pueda haber realizado la Inspección.

Se mantienen, como no podría ser de otra manera, los plazos de los que Inspección y Gestoras disponen, para formular sus respectivas propuestas, que en todo caso deberán estar fundadas y razonadas y esperemos que no estereotipadas, como habitualmente ocurre con otras prestaciones, salvo honrosas excepciones.

En cualquier caso, la situación de Incapacidad Temporal se prorrogará un máximo de 18 días, dependiendo, este plazo, de los derroteros que haya podido ir tomando la discrepancia.

En cumplimiento de la previsión legal de desarrollar reglamentariamente las comunicaciones con los distintos agentes intervinientes, se pone a ello el art. 3 y así sus reglas tercera, cuarta y quinta designan a los obligados a efectuarlas, el objeto de las mismas y la preferencia por los medios electrónicos, informáticos o telemáticos para efectuarlas.

Como se había adelantado, la Disposición Adicional decimonovena de la Ley 40/07 compelía a desarrollar reglamentariamente un procedimiento administrativo de revisión de las altas médicas, expedidas en los procesos de Incapacidad Temporal por las Mutuas y las Empresas colaboradoras (Reglamentariamente se regulará el procedimiento administrativo de revisión, por el Instituto Nacional de la Seguridad Social y a instancia del interesado, de las altas que expidan las entidades colaboradoras en los procesos de Incapacidad Temporal).

Es obvio que el trabajador puede también reaccionar frente al alta emitida por los facultativos de estas entidades, por considerarla indebida, o por no estar conforme con la naturaleza de la contingencia.

La regulación del que se ha venido a denominar procedimiento especial de revisión, parte de unas premisas básicas; a saber, se refiere a las altas dadas por las Mutuas o por las empresas que colaboran voluntariamente en la gestión, respecto de aquellas que se hayan emitido con anterioridad al 
transcurso de los 12 meses (aunque está previsto el que el proceso iniciado con anterioridad supere el referido plazo, en cuyo caso se resolvería de conformidad con lo dispuesto en el art. 128.1.a) de la LGSS) y siempre que se trate de contingencias de carácter profesional.

Cabe considerar, que si bien es elemental que las discrepancias relativas al carácter común o profesional de la contingencia de la Incapacidad Temporal se solventen por las Gestoras, según lo regulado ahora expresamente en este RD, pese a que ello se contenía en la genérica atribución prevista en el art. 1 del RD 1300/95, se desconoce la razón por la que el control de la Incapacidad Temporal, el control puramente médico relativo a la procedencia del alta otorgada, se ha excluido del conocimiento de la Inspección Médica Sanitaria, atribuyéndola a la gestora de la prestación económica, aunque sin duda cualquier estudioso de la Seguridad Social puede recordar que se trata de controlar el gasto. Esta es la única finalidad posible, lo cual se aleja de la deseada revisión del acierto de la decisión médica ( que es lo que supone el alta médica).

Se debe indicar, igualmente, que la autorización legal para conocer estas revisiones se otorga exclusivamente al INSS, y en el RD 1430/2010 se le confieren competencias al ISM, por lo que nos podríamos encontrar con alguna extralimitación reglamentaria.

Este procedimiento, que tradicionalmente se resolvía remitiéndolo a la Mutua por la Gestora con el lacónico "por no ser competente" o "por ser asunto de su competencia", se ha convertido en una pesadilla administrativa para la gestión diaria, que tiene que comenzar por un proceso de clasificación de las peticiones de los interesados, que, por regla general, desconocen los matices de los que venimos ocupándonos, y utilizan los mismos modelos estereotipados para todo, al margen de las especificidades de su proceso de IT.

No obstante lo anterior, al igual que sucede con el procedimiento de discrepancia, este se inicia a instancia de parte, que deberá reaccionar en el plazo de cuatro días naturales siguientes a la notificación del alta, presentando la solicitud ante las gestoras (no se regula la posibilidad de hacerlo ante otros órganos administrativos, aunque lógicamente podrá hacerse), en el modelo que tendrá a disposición en la Web; del mismo modo deberá comunicárselo a su empresa, el mismo día o el hábil siguiente.

Ahora bien, junto con la solicitud deberá aportar su historial clínico relacionado con su proceso de IT, o en su caso justificar que lo ha solicitado, aportando copia de su solicitud, y ello pese a que la Gestora deberá recabar esta información, amen de un informe relativo a las causas del alta a la entidad colaboradora que tramitó el alta.

La simple presentación de la solicitud opera como detonante de la prorroga, sin solución de continuidad, de la situación de Incapacidad Temporal, con las consecuencias inherentes a ello: cobro del subsidio en la modalidad de pago delegado, incompatibilidad con el trabajo y con la percepción de 
salarios, obviedad que recuerda el apartado 11 del art. 4, máxime si se ha comunicado el inicio de este procedimiento a la empresa, lo que en principio impediría la reincorporación a la actividad profesional.

La norma, en previsión de que se presenten procedimientos de revisión infundados y que tengan como único objetivo prolongar unos días el percibo del subsidio y la propia situación de IT, trata de poner la venda antes de la herida, declarando el carácter de indebidamente percibidas las prestaciones que se hubieran abonado al interesado, de confirmarse el alta o con posterioridad a la nueva fecha de extinción que se hubiera podido determinar.

Esta disposición se encuentra en sintonía con la permanente y errónea idea de que el fraude debe y puede presumirse, y si bien es cierto, que en ocasiones existirán conductas dirigidas a la obtención fraudulenta del subsidio, o a prologar la "baja" ( piensen, que el interesado tiene pendiente el pago de una indemnización de una aseguradora por un accidente de tráfico, y en cómo se podrá incrementar en función del mayor número de días impeditivos, que se puedan acreditar), que podrían ser sancionadas de conformidad con las previsiones de la LISOS; no lo es menos, que, en otras, el interesado habrá discrepado de buena fe y sin ningún tipo de voluntad fraudulenta, en el absoluto convencimiento de no encontrarse apto para reanudar su actividad laboral, con las graves consecuencias de verse privado de su salario y obligado a devolver el subsidio, de conformidad con el art. 45 de la LGSS, amén de que una vez más surgirán las discrepancias en torno a si las deducciones efectuadas por la empresa, que anticipo el pago delegado, están o no bien efectuadas o si es la Gestora o la colaboradora la que debe dirigirse frente al trabajador para reclamar lo indebidamente percibido.

Contrasta este tratamiento, con el dispensado al trabajador que discrepa del alta acordada por el INSS a los doce meses, que con solo iniciar el procedimiento, lo ve igualmente prorrogado, pero no viene obligado a devolver lo percibido, aunque se confirme el alta.

Llegados a este punto, presentada la solicitud, las Gestoras lo comunicarán a la Mutua que corresponda y a la empresa, que ya debería haber recibido la comunicación por el trabajador Los plazos se hacen asfixiantes, la Mutua en dos días, plazo improrrogable, deberá o reconocer la improcedencia de su actuar, lo que determinará el inmediato archivo, o remitir los antecedentes de los que disponga, pues de no hacerlo la Gestora resolverá con lo aportado por el trabajador.

A diferencia de la comunicación a la Mutua donde no se señala plazo de remisión, sí que deberá estarse al fijado para la notificación a la empresa y que será el de dos días, desde la presentación de la solicitud por el interesado.

Como será habitual, al menos con una frecuencia superior a la deseable, el trabajador habrá tratado de obtener y generalmente conseguir la baja de "su médico de cabecera", que diligentemente y sin que precise de folletos 
informativos o de procelosas normas, habrá llevado a su empresa un pariente o él mismo, pese a que ahora no sea necesario, pues la simple acreditación de la presentación del procedimiento especial de revisión habrá servido a sus fines. En este supuesto, y, acertadamente, se compele (deberá) a la empresa a que lo comunique a la entidad gestora, de forma inmediata, con el loable fin (por fin) de coordinar las actuaciones que procedan.

La dirección Letrada de las entidades gestoras han sido sufridores de aquellos procedimientos en los que la Mutua daba al trabajador de alta y este acudía a obtener la baja de su médico de cabecera, que era expedida de forma inmediata, para, a su vez, la entidad gestora, no abonar el subsidio de IT por considerar que la contingencia profesional era responsabilidad de la Colaboradora, obligando al trabajador a un inimaginable peregrinar en el tiempo por los distintos órganos judiciales.

Esta situación, absolutamente injusta, es abordada por el Real Decreto, de tal forma que si se detecta la existencia de un proceso de IT por contingencia profesional, concatenado con el que conoce el Servicio Público de Salud, éste deberá informar al interesado sobre la posibilidad de iniciar, en el plazo de los cuatro días siguientes al de notificación del alta médica emitida por la entidad colaboradora ( y que no hayan transcurrido, que será lo habitual ante la celeridad con la que se acude al galeno), este procedimiento especial de revisión y, además, inmediatamente se comunicará a la entidad gestora competente la existencia de dos procesos distintos de Incapacidad Temporal que puede que esten relacionados.

Lo que se valora positivamente, es que en ambos supuestos, esto es cuando exista incoado el procedimiento especial y se presente una baja del SPS, o, cuando sin haberse iniciado, el trabajador solicite la baja derivada de riesgo común, se iniciará el abono de la prestación por contingencias comunes, hasta la fecha de resolución del procedimiento.

La regulación es, en extremo, farragosa e incoherente. En efecto, se debe tener presente el último párrafo del apartado 5 de este artículo que dice textualmente " en estos casos" los referidos en los dos párrafos anteriores " se iniciará el abono... hasta la fecha de la resolución del procedimiento...", ignorando no sé sabe si consciente o inconscientemente, que el supuesto del segundo párrafo descansa sobre la premisa de que no se ha iniciado el procedimiento especial, de forma tal, que quien tenga asegurado el riesgo por contingencias comunes deberá tener que seguir pagando el subsidio, o incoar de oficio un expediente de determinación de contingencia.

Pongamos otro ejemplo, si la mera iniciación del procedimiento no impide que se continúe con el abono del subsidio en régimen de pago delegado ( art.4.3), lógicamente, si existe la posibilidad de que sea emitida una baja por riesgos comunes sin solución de continuidad ( art. 4.5) no se entiende, el que deba procederse al pago de la prestación por riesgos comunes, como parece deducirse del tercer párrafo del $\mathrm{n}^{\circ} 5$ del mismo artículo, que afirma que en estos casos se iniciará su abono. 
Todo ello sin perjuicio, de que si el alta de la colaboradora no produce efecto alguno, ésta deba reintegrar a la entidad gestora la prestación abonada al interesado y a éste la diferencia que resulte a su favor (¿estamos ante un nuevo supuesto de pago directo?, ¿no es posible que las contingencias derivadas de riesgos comunes estén cubiertas por la misma entidad colaboradora?) ¿ no habíamos quedado, en que el inicio de este procedimiento no impedía que se siguiera manteniendo el pago?.

Únicamente, se alcaza a atisbar una interpretación lógica, si se entiende lo siguiente, a saber; cuando en el número 3 se señala que el abono se mantendrá, en su caso, esta expresión sólo se puede estar refiriendo a aquellos supuestos en los que se detecte que se abonará el subsidio de conformidad con lo dispuesto en el párrafo tercero del número 5 por riesgos comunes, en cuyo caso no se abonará la prestación por riesgos profesionales y de esta forma se cumplirá la premisa para que la Gestora pueda ser resarcida de lo abonado al trabajador y las diferencias al interesado.

No es menos cierto, que la regulación haya podido pretender anticipar comportamientos de administrados, que no sean conscientes de que la iniciación del procedimiento prorroga automáticamente la situación de Incapacidad Temporal y que no es preciso instar de los servicios sanitarios una nueva baja.

Como todo expediente administrativo, éste que nos ocupa, finalizará con la resolución del Director Provincial, que se deberá emitir en el plazo de 15 días hábiles a contar a partir de la aportación por la entidad colaboradora de la documentación requerida, debiendo entender que, de no ser remitida, el plazo será el mismo contado desde la fecha en la que le sea requerido, o a lo sumo a partir del primer día hábil siguiente al que debió ser remitida, aunque nada se diga, presumiendo que lo que se ha pretendido es no hacer más imbricada y espesa la redacción del precepto.

Resulta altamente significativo el que, a diferencia del procedimiento de discrepancia, que parte de una propuesta de alta del facultativo del INSS que ha revisado al interesado, en este procedimiento, lo preceptivo sea el informe del EVI, que debería descansar sobre la premisa de un examen y revisión del interesado por parte de los médicos del INSS o del ISM, sólo pudiendo entenderse así la referencia a que el Informe del EVI debe responder al examen y valoración del caso concreto y no a una simple revisión documental, tanto para garantizar lo acertado de la resolución como el éxito de una futura reclamación judicial.

La resolución determinará la fecha y efectos del alta médica o el mantenimiento de la baja, fijando en su caso, la contingencia de la que deriva el proceso de IT, si bien reservado para aquellos casos en los que la empresa comunique la presentación de una nueva baja médica por contingencias comunes, cuando se le comunique por la Gestora que su trabajador ha iniciado el procedimiento especial de revisión. No para otros supuestos. Como se ha puesto de manifiesto, igualmente podrá declarar la improcedencia de 
otras bajas médicas que pudieran haberse emitido durante la tramitación del procedimiento especial.

En definitiva, la norma enumera los pronunciamientos que se podrán adoptar:

a) Confirmación del alta médica, emitida por la Mutua de accidentes de trabajo y enfermedades profesionales de la Seguridad Social, y declaración de la extinción del proceso de Incapacidad Temporal en la fecha de la mencionada alta.

b) Mantenimiento de la situación de Incapacidad Temporal derivada de riesgo profesional, por considerar que el interesado continúa con dolencias que le impiden trabajar. Por tanto, el alta médica emitida por la entidad colaboradora no producirá efecto alguno.

c) Determinación del riesgo, común o profesional, del que derive la situación de Incapacidad Temporal, cuando coincidan procesos intercurrentes en el mismo periodo de tiempo, y, por tanto, existan distintas bajas médicas. Asimismo, se fijarán los efectos que correspondan, en el proceso de Incapacidad Temporal, como consecuencia de la determinación del riesgo causante.

d) Cuando el interesado hubiera recuperado la capacidad laboral durante la tramitación del procedimiento, se podrá declarar, sin efectos, el alta médica emitida por la entidad colaboradora por considerarla prematura. En estos casos, la resolución determinará la nueva fecha de efectos del alta médica y de extinción del proceso de Incapacidad Temporal.

Las resoluciones emitidas por la entidad gestora, en el ejercicio de las competencias establecidas en este artículo, podrán considerarse dictadas con los efectos atribuidos a la resolución de una reclamación previa, de conformidad con lo dispuesto en el artículo 71 del texto refundido de la Ley de Procedimiento Laboral, aprobado por el Real Decreto Legislativo 2/1995, de 7 de abril, lo que se hará constar en la resolución que se dicte.

La pregunta surge automáticamente ¿Cuando se deberá entender por la Gestora que la resolución debe ser considerada como resolución que resuelve una reclamación previa, y cuándo no?

A modo de conclusión. Los mecanismos de gestión de esta prestación son complejos, intervienen una pluralidad de entes y organismos (Entidades Gestoras, Mutuas, empresas, Servicios Públicos de Salud) con responsabilidades y competencias específicas y concretas absolutamente interrelacionadas, y exigían desde hace ya mucho tiempo una elemental coordinación de todos ellos, pues se ha expuesto y todos hemos sido testigos, de las situaciones que la descoordinación puede llegar a provocar.

Este objetivo se comenzó a perfilar con la suscripción de los Convenios interadministraciones, pero ha encontrado su concreción con la Ley 40/07 y 
su norma de desarrollo, el RD 1430/2009; si bien aún es pronto para valorar los resultados, al igual que la apuesta de hacer recaer sobre las Entidades Gestoras el control efectivo de la prestación, en detrimento de los Servicios Públicos de Salud, a lo que se añadiría que no se deberá prescindir de la colaboración de las Mutuas cuya incorporación a la gestión de la Incapacidad Temporal ha sido importantísima, según la posibilidad que reguló el art. 35 de la Ley 42/94, de 30 de Diciembre, de Medidas Fiscales, Administrativas y del orden Social, facultando al empresario a formalizar la cobertura de la IT derivada de riesgos comunes con la Mutua con la que previamente tuviesen asegurados los riesgos profesionales.

La posterior Ley 66/97, y RDL 6/2000 que reconoció a los facultativos de estas entidades la facultad de expedir altas médicas en los procesos de IT por riesgos comunes) se ha visto ninguneada por una incomprensible oposición sindical para que los médicos de estas entidades, puedan dar altas médicas, pese a que a ello les autoriza, como hemos destacado, la ley.

Además, debe continuarse con la medida de incrementar los recursos humanos y materiales en la Entidad Gestora, no sólo por que la mejor dotación en las Mutuas determinaba la opción por la cobertura de contingencias por las empresas, sino por que el legislador ha primado las competencias del INSS sobre aquellas y, por tanto también las funciones a desarrollar. Pero es que, además, esta falta de medios personales es lo que impidió poner en marcha la reforma introducida por la Ley 30/05 (iniciada en enero de 2006 y culminada en enero de 2008).

Se tiene que incidir en la formación en materia de gestión de la Incapacidad Temporal, porque el control de la Incapacidad Temporal tiene que limitarse al control de los partes de baja expedidos por los facultativos del Servicio Público de Salud. Por tanto, el control médico no puede venir condicionado al cumplimientos de índices de productividad ( en el momento actual de emisión del 20\% de altas médicas en los pacientes revisados).

En esta mismo línea debe desterrarse la idea de voluntariedad en el acceso a la situación de Incapacidad Temporal.

Aunque se han realizado Convenios con las Comunidades autónomas, deberá, en el seno de estos, acordarse la unificación de los códigos diagnósticos así como la necesidad de consignar todas las patologías y no sólo una de ellas, y continuar con la coordinación entre las entidades implicadas en la gestión, porque es algo necesario si tenemos en cuenta que quien genera el gasto (Servicio Público de Salud) debe también controlarlo, aunque no sea el pagador (INSS y Mutuas). Necesario porque tras el alta del INSS ( antes de 12 meses) puede el Servicio público de salud expedir baja médica y, por que tras la finalización de un proceso de Incapacidad derivado de riesgo profesional, antes de 12 meses, puede expedirse baja médica por riesgos comunes e iniciarse procedimiento de determinación del riesgo determinante de la contingencia ante el INSS, que, en la práctica, supone acceder, por vía indirecta, a la prolongación del proceso de Incapacidad Temporal, cuya alta no fue impugnada. 
Son muchas más las cuestiones que se pueden plantear porque la evolución normativa descrita se decantó, en un primer momento hacia el control de la IT en las Mutuas, para pasar a la actual tendencia del control público, si bien la dinámica del funcionamiento de los Servicios públicos sanitarios dificulta el control de la Incapacidad Temporal, que, como se ha manifestado, debe ser fundamentalmente médico. 